\title{
Rhodococcus opacus B4: a promising bacterium for production of biofuels and biobased chemicals
}

\author{
Ana Rita Castro, Isabel Rocha, Maria Madalena Alves and Maria Alcina Pereira*
}

\begin{abstract}
Bacterial lipids have relevant applications in the production of renewable fuels and biobased oleochemicals. The genus Rhodococcus is one of the most relevant lipid producers due to its capability to accumulate those compounds, mainly triacylglycerols (TAG), when cultivated on different defined substrates, namely sugars, organic acids and hydrocarbons but also on complex carbon sources present in industrial wastes. In this work, the production of storage lipids by Rhodococcus opacus B4 using glucose, acetate and hexadecane is reported for the first time and its productivity compared with Rhodococcus opacus PD630, the best TAG producer bacterium reported. Both strains accumulated mainly TAG from all carbon sources, being influenced by the carbon source itself and by the duration of the accumulation period. R. opacus B4 produced 0.09 and $0.14 \mathrm{~g} \mathrm{~L}^{-1}$ at 24 and $72 \mathrm{~h}$, with hexadecane as carbon source, which was 2 and 3.3 fold higher than the volumetric production obtained by R. opacus PD630. Both strains presented similar fatty acids (FA) profiles in intact cells while in TAG produced fraction, $R$. opacus B4 revealed a higher variability in fatty acid composition than $R$. opacus PD630, when both strains were cultivated on hexadecane. The obtained results open new perspectives for the use of $R$. opacus B4 to produce TAG, in particular using oily (alkane-contaminated) waste and wastewater as cheap raw-materials. Combining TAG production with hydrocarbons degradation is a promising strategy to achieve environmental remediation while producing added value compounds.
\end{abstract}

Keywords: Rhodococcus opacus, Lipids, Hexadecane, Triacylglycerols, Fatty acids, Biodiesel

\section{Introduction}

In the last years, attention has been paid to microbes as lipid producers for biotechnological and industrial applications. Bacterial lipids such as triacylglycerol (TAGtriesters of glycerol and long-chain fatty acids) and wax esters (WE-esters of primary long-chain fatty acids and primary long chain fatty alcohols), have relevant applications in the production of food additives, cosmetics, lubricants, oleochemicals, candles and biofuels (Röttig et al. 2010; Holder et al. 2011). The majority of the bacterial species synthesizes polyhydroxyalkanoates (PHA) as storage compounds (Alvarez et al. 1997a; Steinbüchel and Hein 2001), whereas the ability to accumulate TAG and WE has been reported for only some genera (Alvarez

\footnotetext{
*Correspondence: alcina@deb.uminho.pt

CEB-Centro de Engenharia Biológica, Universidade do Minho, Campus de Gualtar, 4710-57 Braga, Portugal
}

and Steinbüchel 2002). The amount, composition and structure of bacterial lipids are dependent on several factors, including the bacterial species itself, the carbon source used, the time of cultivation and the amount of carbon and nitrogen present in the culture medium (Packter and Olukoshi 1995; Alvarez et al. 1997a, 1997b; Wältermann et al. 2005). Among several TAG accumulating genera, the genus Rhodococcus is one of the most promising, because some strains can accumulate more than $20 \%$ of their biomass as TAG, being considered oleaginous bacteria. Members of this genus can be found in several types of natural environments, from arid and tropical soils to cold ecosystems and marine sediments (Whyte et al. 1999; Heald et al. 2001; Luz et al. 2004; Peng et al. 2008). Additionally, Rhodococcus can produce and accumulate TAG from several types of substrates under nitrogen-limiting conditions, including defined carbons sources like sugars, organic acids or hydrocarbons 
(Alvarez et al. 1996, 1997a, 2000; Silva et al. 2010) but also complex carbon sources present in industrial wastes (Voss and Steinbuchel 2001; Gouda et al. 2008), revealing a remarkable versatility in terms of substrate degradation.

Within the last decade, reports of new TAG accumulating species of Rhodocococcus have considerably increased, for example $R$. ruber, $R$. fascians, $R$. erythropolis, $R$. jostii, $R$. aetherivorans IAR1, R. sp 602 and $R$. sp. A5 (Alvarez et al. 1997a, 2000; Kalscheuer et al. 2001; Alvarez 2003; Hernandez et al. 2008; Hori et al. 2009; Silva et al. 2010; Bequer Urbano et al. 2013). Rhodococcus opacus PD630 is the best studied bacterium concerning TAG production and accumulation. This bacterium has the ability to accumulate significant amounts of lipids, namely 76 and $87 \%$ $(\mathrm{w} / \mathrm{w})$ of the cellular dry weight $(\mathrm{CDW})$, when grown on gluconate and olive oil, respectively (Alvarez et al. 1996; Voss and Steinbüchel 2001). Additionally, it can accumulate TAG under cultivation on other carbon sources, such as alkanes, acetate, glucose, propionate, among others (Alvarez et al. 1996; Wältermann et al. 2000; Alvarez and Steinbüchel 2010). For these reasons, R. opacus PD630 is considered a model bacterium. However, to develop sustainable lipids producing processes using Rhodococcus sp. and to increase the knowledge of TAG metabolism and physiology in this species it is mandatory to get further insights on lipid accumulation and also to identify new Rhodococcus strains possessing this feature. $R$. opacus B4 was isolated from a gasoline-contaminated soil in Japan. This bacterium is highly tolerant to several organic solvents, can use benzene as a sole source of carbon and energy and metabolizes aromatic and aliphatic hydrocarbons ( $\mathrm{Na}$ et al. 2005; Yamashita et al. 2007; Sameshima et al. 2008). Moreover, it has the capacity to stabilize water-oil emulsions, which can be important in bioremediation processes (Honda et al. 2008; Hamada et al. 2009). However, the ability to produce and accumulate lipid storage compounds was never reported. In the present work, the ability of $R$. opacus B4 to produce and accumulate lipid storage compounds was investigated, using different carbon sources and accumulation period lengths. $R$. opacus PD630 was used under the same cultivation conditions as a comparative well characterized bacterium.

\section{Materials and methods}

Bacterial strains, media and cultivation conditions

\section{Strains and media}

Rhodococcus opacus PD630 (DSM 44193) and Rhodococcus opacus B4 (NBRC 108011) were purchased from the Deutsche Sammlung von Mikroorganismen und Zellkulturen (DSMZ) and Biological Resource Center, NITE (NBRC), respectively. R. opacus PD630 was isolated from a soil sample collected at a gas-works plant in Germany (Alvarez et al. 1996) and R. opacus B4 was isolated from an oil sample taken from a gasoline contaminated roadside in Hiroshima, Japan (Na et al. 2005).

The culture media used for maintenance and growth of bacterial strains were 802 medium containing $\left(\mathrm{g} \mathrm{L}^{-1}\right)$ 10.0 polypeptone; 2.0 yeast extract and $1.0 \mathrm{MgSO}_{4} \cdot 7 \mathrm{H}_{2} \mathrm{O}$ and mineral salts (MS) medium according to (Schlegel et al. 1961. Glucose $\left(40 \mathrm{~g} \mathrm{~L}^{-1}\right)$, sodium acetate $\left(10 \mathrm{~g} \mathrm{~L}^{-1}\right)$ or hexadecane $\left(1 \mathrm{~g} \mathrm{~L}^{-1}\right)$ were used as carbon and energy sources. For solid media, $1.5 \%$ agar was added to the MS and 802 media. The cells were grown at $30{ }^{\circ} \mathrm{C}$ and $150 \mathrm{rpm}$ under the conditions described below.

\section{Preparation of seed cultures}

Cells from a single colony of $R$. opacus B4 and $R$. opacus PD630, grown on 802 medium agar plates at $30{ }^{\circ} \mathrm{C}$ for 4 days, were separately inoculated in $50 \mathrm{~mL}$ of 802 medium in $250 \mathrm{~mL}$ flasks. The seed cultures were incubated on a rotary shaker $(150 \mathrm{rpm})$ at $30{ }^{\circ} \mathrm{C}$ until the middle of the exponential growth phase was reached (48 h for $R$. opacus B4 and $24 \mathrm{~h}$ for $R$. opacus PD630). Growth of the seed cultures was determined by measuring optical density at $600 \mathrm{~nm}(\mathrm{~nm})$ wavelength with a spectrophotometer (U-1500 Hitachi, Tokyo, Japan).

\section{Growth and lipid accumulation experiments}

The experiments were divided in two cultivation stages. In stage I, culture conditions promoted high cell densities (growth conditions) while in stage II neutral lipid accumulation was promoted (storage conditions). MS medium supplemented with glucose $(4 \%, \mathrm{w} / \mathrm{v})$, sodium acetate $(0.6 \%, \mathrm{w} / \mathrm{v})$ or hexadecane $(0.3 \%, \mathrm{w} / \mathrm{v})$ as sole carbon sources was used for cultivation.

The two-stage experiments were carried out under sterile conditions in duplicate using $250 \mathrm{~mL}$ conical flasks containing $50 \mathrm{~mL}$ of defined medium and incubated on a rotary shaker $(250 \mathrm{rpm})$ at $30^{\circ} \mathrm{C}$. In stage I, cells of seed cultures were harvested, washed with sterile $\mathrm{NaCl}$ solution $(0.9 \%, \mathrm{w} / \mathrm{v})$, and suspended in fresh MS medium. Cells were used to inoculate flasks to an optical density (OD) at $600 \mathrm{~nm}$ of 0.1 . Cultures of both strains were cultivated in MS medium at a molar carbon to nitrogen ratio of 68 for glucose $(\mathrm{C} / \mathrm{N}=68), 8$ for acetate $(\mathrm{C} / \mathrm{N}=8)$ and 4 for hexadecane $(\mathrm{C} / \mathrm{N}=4)$. Cells were grown until the middle of the exponential growth phase, namely 32, 50 and $150 \mathrm{~h}$ for glucose, acetate and hexadecane, respectively.

For stage II, cells from stage I were collected by centrifugation $\left(4^{\circ} \mathrm{C}, 10 \mathrm{~min} ., 10,000 \mathrm{~g}\right)$, washed twice with sterile $\mathrm{NaCl}$ solution $(0.9 \% \mathrm{w} / \mathrm{w})$ and transferred to fresh MS medium with lower nitrogen concentration, with a $\mathrm{C} / \mathrm{N}$ ratio of 300 for all carbon sources, in order to promote neutral lipid accumulation. After 24 and $72 \mathrm{~h}$ of cultivation, cells were harvested, washed and kept at $-80{ }^{\circ} \mathrm{C}$ until further lyophilization. 


\section{Substrate consumption Glucose and acetate}

Samples from the culture medium of both strains were collected in stage II at 0,24 and $72 \mathrm{~h}$ to analyze substrate concentration. Glucose and acetate were measured by high-performance liquid chromatography (Jasco, Japan) using a Chrompack column $\left(6.5 \times 30 \mathrm{~mm}^{2}\right)$. The mobile phase used was sulfuric acid $(0.01 \mathrm{~N})$ at a flow rate of $0.6 \mathrm{~mL} \mathrm{~min}{ }^{-1}$. The column temperature was set at $60{ }^{\circ} \mathrm{C}$. Detection of compounds was performed by using an UV detector at $210 \mathrm{~nm}$ for acetate and a refraction index (RI) detector for glucose.

\section{Hexadecane}

For hexadecane analysis, total content of the cultivation flask (50 mL of culture medium) was acidified with $\mathrm{HCl} 8 \mathrm{M}$ to $\mathrm{pH} 2$ and stored at $4{ }^{\circ} \mathrm{C}$ (for no longer than 14 days) until extraction. Hexadecane present in the culture medium was extracted using a liquid-liquid extraction procedure. Before extraction, tetradecane was added as a surrogate to evaluate the efficiency of the extraction process. The extraction was serially performed three times with $15 \mathrm{~mL}$ of hexane. Between the serial extractions, the funnels were vigorously shaken for $2 \mathrm{~min}$. After 10 to 30 min rest (depending on the sample), the organic layer was collected.

The extract was passed through a Sep-Pak Florisil 6 cc column (Waters, USA) using a Supelco ${ }^{\circledR}$ vacuum Manifold system. The column was previously preconditioned with $5 \mathrm{~mL}$-hexane. In the end, an additional $5 \mathrm{~mL}$-hexane was added to the column to ensure that all hexadecane was eluted. Then, sodium thiosulfate was added to remove residual aqueous residues. The extracts were kept in glass flasks in fume hood until dryness, reconstituted in $1 \mathrm{~mL}$ $\mathrm{n}$-hexane and stored at $-20^{\circ} \mathrm{C}$ until analysis. Hexadecane concentration was determined using a gas chromatograph with a flame ionization detector (GC-FID) (GC Varian ${ }^{\circledR}$ star 3400 CX, USA). Undecane (C11) was used as internal standard and was added to the samples before GC analysis. The column used was the model VF-1 ms (Agilent, USA) $30 \mathrm{~m}$ length long $\times 0.025 \mathrm{~mm}$ internal diameter, made from fused silica coated with dimethylpolysiloxane as stationary phase. Helium was used as carrier gas at $1 \mathrm{~mL} \mathrm{~min}{ }^{-1}$. The temperature of the detector and the injector were set at 300 and $285^{\circ} \mathrm{C}$, respectively. The column's temperature was maintained at $60^{\circ} \mathrm{C}$ for $1 \mathrm{~min}$ and then programmed up to $290^{\circ} \mathrm{C}$ at a rate of $8{ }^{\circ} \mathrm{C} \mathrm{min}^{-1}$.

\section{Extraction and analysis of cellular lipids Lipid extraction}

Lipids were extracted according to Folch method (Folch et al. 1957), with some modifications. $15 \mathrm{mg}$ of lyophilized cells were extracted with $3 \mathrm{~mL}$ of a mixture of chloroform/methanol (2:1, v/v) (Wältermann et al. 2000). The mixture was incubated at room temperature with shaking for $2 \mathrm{~h}$. The crude extract was filtered through a Pasteur pipette packed with glass wool (1.5 $\mathrm{cm}$ packing) to separate the cell debris and salts and afterwards evaporated to dryness.

\section{Neutral lipid detection by $T L C$}

Analysis of lipid content in $R$. opacus $\mathrm{B} 4$ and $R$. opacus PD630 was performed by thin-layer chromatography (TLC). Lipid extracts were dissolved in chloroform/methanol $(2: 1, \mathrm{v} / \mathrm{v})$. The extracts were applied on $10 \times 10 \mathrm{~cm}$ glass DC-Fertigplatten plates, precoated with $0.25 \mathrm{~mm}$ silica gel 60 with fluorescent indicator UV254 (60F254 silica gel plates-Merck, Darmstadt, Germany). The TLC chromatogram was performed applying the following developing solvent system: hexane/diethyl ether/acetic acid (80:20:1, v/v/v) as mobile phase for TAG analysis (Wältermann et al. 2000).

Neutral lipids were visualized on plates after brief exposure to iodine vapor. Olive oil, oleic acid, and oleyl oleate were used as standard substances for TAG, FA and WE, respectively.

\section{TAG quantification}

After evaporation of iodine, TAG bands were scraped from the TLC plates and transfer to a Pasteur pipet containing glass wool. TAG fraction was eluted from Silica Gel by adding three times $1 \mathrm{~mL}$ chloroform and transferred to a previously weighted glass flask. Chloroform was evaporated in the fume hood and TAG amounts were determined gravimetrically (Santala et al. 2011).

\section{Analysis of cellular fatty acid content and composition}

Approximately $15 \mathrm{mg}$ of whole lyophilized cells or $5 \mathrm{mg}$ of TAG fraction obtained from TLC (depending on the strain) were submitted to methanolysis in the presence of $15 \%$ (v/v) sulfuric acid (Brandl et al. 1988; Timm et al. 1990). Briefly, samples were added to Teflon screwcapped glass test tubes, mixed with $1.5 \mathrm{~mL}$ chloroform to which $3 \mathrm{ml}$ of a 85:15 methanol/sulphuric acid solution was added. The tubes were heated at $100{ }^{\circ} \mathrm{C}$ for $3.5 \mathrm{~h}$. Subsequently, $1 \mathrm{~mL}$ of ultra-pure water was added, and the samples were vortexed for $1 \mathrm{~min}$, and after phase separation (approximately $30 \mathrm{~min}$ ), the organic phase was collected, containing the fatty acid methyl esters. Heptanoic acid (C7:0) and pentadecanoic acid (C15:0) were used as internal standards, added to the samples before methanolysis takes place $(1.5 \mathrm{~mL})$. Methyl esters were quantified in a GC-FID (Varian 3800). FAMEs were separated on a CP-Sil 52 CB $30 \mathrm{~m} \times 0.32 \mathrm{~mm} \times 0.25 \mu \mathrm{m}$ capillary column (Teknokroma, TR-WAX). One microlitre portion of the organic phase was analyzed using a 
splitless mode. Helium was used as carrier gas at a flow rate of $1.0 \mathrm{~mL} \mathrm{~min}^{-1}$. A temperature program was established for an efficient separation of the methyl esters. Initial oven temperature was set at $50^{\circ} \mathrm{C}$ for 2 min with an increase of $10{ }^{\circ} \mathrm{C} \mathrm{min}{ }^{-1}$ to a final temperature of $225^{\circ} \mathrm{C}$. Injector and detector temperatures were set at 220 and $250{ }^{\circ} \mathrm{C}$, respectively. FA were identified by comparison of the respective retention factor values (Rf) of standard fatty acid methyl esters.

\section{Statistical analysis}

Significant differences between biological samples, cultivated on different carbon sources and on different accumulation periods, were evaluated using two factor analyses of variances (ANOVA), using SPSS 22.0.0 statistical software. Statistical significance was established at the $\mathrm{p}<0.05$ level.

\section{Results}

\section{Biomass production and substrate degradation}

In both strains, maximum biomass density was obtained with glucose, whereas the minimum was achieved with hexadecane as carbon source (Table 1). A significant increase in biomass production by increasing the incubation period (from 24 to $72 \mathrm{~h}$ ) was observed when cells of $R$. opacus B4 were cultivated on glucose, reaching the highest value observed for this strain, namely $3.3 \pm 0.01 \mathrm{~g}$ $\mathrm{L}^{-1}(\mathrm{p}<0.05)$. On the other hand, the effect of incubation time in $R$. opacus PD630 was not observed, although it was able to reach higher cell densities than $R$. opacus B4 at 24 and $72 \mathrm{~h}$, namely 1.5 - and 1.3 -fold more $(\mathrm{p}<0.05)$.

$R$. opacus $\mathrm{B} 4$ presented higher growth than $R$. opacus PD630 using hexadecane as carbon and energy source. When incubation time was increased to $72 \mathrm{~h}, R$. opacus B4 doubled biomass concentration to a density of $0.837 \pm 0.281 \mathrm{~g} \mathrm{~L}^{-1}$ while $R$. opacus PD630 presented similar values in both incubation times, but about half of the obtained for $R$. opacus $\mathrm{B} 4(\mathrm{p}<0.05)$. Acetate had a different behavior when compared to the other carbon sources. For both strains, there was a $35 \%$ decrease in CDW from 24 to $72 \mathrm{~h}$ incubation period $(\mathrm{p}<0.05)$.

Regarding substrate consumption, there was a general increase with incubation time for both strains and for all carbon sources (Table 1). Cells of $R$. opacus B4 consumed less glucose in the first $24 \mathrm{~h}(8.1 \pm 4.1 \%)$ when compared to $R$. opacus PD630 $(22.8 \pm 0.8 \%)(\mathrm{p}<0.05)$. When cultivated on hexadecane, $R$. opacus B4 degraded more substrate at $24 \mathrm{~h}(70.5 \pm 5.1 \%)$ than $R$. opacus PD630 $(52.6 \pm 9.6 \%)(\mathrm{p}<0.05)$. Acetate was almost entirely consumed by both strains during the first $24 \mathrm{~h}$ incubation

Table 1 Cell dry matter (CDW), triacylglycerol (TAG) content, \% of substrate degradation and TAG yields in cells of $R$. opacus B4 and $R$. opacus PD630

\begin{tabular}{|c|c|c|c|c|c|c|}
\hline Strain & $\begin{array}{l}\text { Carbon } \\
\text { source }\end{array}$ & Time (h) & CDW $\left(\mathrm{g} \mathrm{L}^{-1}\right)$ & TAG $\left(\mathbf{g ~ g}^{-1} \mathrm{CDW}\right)$ & $\begin{array}{l}\text { Substrate } \\
\text { consumed (\%) }\end{array}$ & $\begin{array}{l}\text { TAG yield ( } \mathbf{g ~ g}^{-1} \\
\text { substrate consumed) }\end{array}$ \\
\hline \multirow[t]{9}{*}{ R. opacus B4 } & Glucose & 0 & $2.2^{\mathrm{a}}$ & $0.044^{\mathrm{a}}$ & & \\
\hline & & 24 & $2.5 \pm 0.04$ & $0.230 \pm 0.045$ & $8.1 \pm 4.3$ & $0.203 \pm 0.068$ \\
\hline & & 72 & $3.3 \pm 0.01$ & $0.217 \pm 0.014$ & $37.4 \pm 5.6$ & $0.054 \pm 0.015$ \\
\hline & Acetate & 0 & $0.45^{\mathrm{a}}$ & $0.081^{a}$ & & \\
\hline & & 24 & $1.1 \pm 0.1$ & $0.252 \pm 0.040$ & $97.3 \pm 0.5$ & $0.054 \pm 0.005$ \\
\hline & & 72 & $0.724 \pm 0.017$ & $0.117 \pm 0.061$ & $100.0 \pm 0.0$ & $0.016 \pm 0.002$ \\
\hline & Hexadecane & 0 & $0.398^{\mathrm{a}}$ & $0.079^{a}$ & & \\
\hline & & 24 & $0.459 \pm 0.134$ & $0.186 \pm 0.021$ & $70.5 \pm 5.1$ & $0.147 \pm 0.069$ \\
\hline & & 72 & $0.837 \pm 0.281$ & $0.170 \pm 0.034$ & $85.2 \pm 17.7$ & $0.194 \pm 0.112$ \\
\hline \multirow[t]{9}{*}{ R. opacus PD630 } & Glucose & 0 & $2.4^{\mathrm{a}}$ & $0.111^{\mathrm{a}}$ & & \\
\hline & & 24 & $3.9 \pm 0.4$ & $0.287 \pm 0.003$ & $22.8 \pm 0.8$ & $0.076 \pm 0.001$ \\
\hline & & 72 & $4.1 \pm 0.5$ & $0.384 \pm 0.051$ & $26.5 \pm 5.8$ & $0.125 \pm 0.024$ \\
\hline & Acetate & 0 & $0.620^{\mathrm{a}}$ & $0.169^{a}$ & & \\
\hline & & 24 & $1.1 \pm 0.01$ & $0.246 \pm 0.015$ & $81.1 \pm 10.4$ & $0.054 \pm 0.003$ \\
\hline & & 72 & $0.726 \pm 0.040$ & $0.444 \pm 0.179$ & $100.0 \pm 0.0$ & $0.059 \pm 0.033$ \\
\hline & Hexadecane & 0 & $0.250^{\mathrm{a}}$ & $0.063^{\mathrm{a}}$ & & \\
\hline & & 24 & $0.321 \pm 0.168$ & $0.141 \pm 0.013$ & $52.6 \pm 9.8$ & $0.070 \pm 0.049$ \\
\hline & & 72 & $0.468 \pm 0.062$ & $0.092 \pm 0.008$ & $94.5 \pm 4.2$ & $0.037 \pm 0.004$ \\
\hline
\end{tabular}

Cells were cultivated in different carbon sources under nitrogen limiting conditions $(C / N=300)$ during 24 and $72 \mathrm{~h}$

The means are the result of at least two independent experiments, \pm standard deviation (s.d.)

a Corresponds to one replicate 
time $(97.3 \%$ in $R$. opacus $\mathrm{B} 4$ and $81.1 \%$ in $R$. opacus PD630), reaching full depletion at $72 \mathrm{~h}$.

\section{Neutral lipids profile, TAG levels and yields}

The patterns of neutral lipids produced by $R$. opacus B4 and by $R$. opacus PD630 are illustrated in Fig. 1. The most intense TLC band observed in all tested conditions corresponds to TAG. Furthermore, FA and WE were also present but in minor amounts. Three additional faint bands of unknown identity were visualized: located below FA, immediately below TAG bands and between TAG and WE.

The highest and the lowest TAG levels were obtained by $R$. opacus PD630 cultivated for $72 \mathrm{~h}$ in acetate and hexadecane, respectively (Table 1). In glucose, differences in cultivation length did not affect significantly TAG levels in $R$. opacus $\mathrm{B} 4$, but an increase of $34 \%$ was observed in $R$. opacus PD630. $R$. opacus PD630 was able to accumulate more TAG than $R$. opacus $\mathrm{B} 4$ especially at $72 \mathrm{~h}$ ( $\mathrm{p}<0.05)$. On acetate, $R$. opacus B4 suffered a decrease of more than $50 \%$ of TAG levels from 24 to $72 \mathrm{~h}$. On the other hand, $R$. opacus PD630 increased TAG production with incubation time, achieving a maximum of $0.444 \mathrm{~g} \mathrm{~g}^{-1} \mathrm{CDW}$ at $72 \mathrm{~h}(\mathrm{p}<0.05)$, which was 3.8 -fold higher $(\mathrm{p}<0.05)$ than the one obtained with $R$. opacus B4.

For hexadecane, the amount of TAG was not affected by incubation time in $R$. opacus $\mathrm{B} 4$ whereas $R$. opacus PD630 had a $35 \%$ decrease in TAG content $(\mathrm{p}<0.05)$.

Regarding TAG yields on substrate, maximum and minimum values were achieved by $R$. opacus $\mathrm{B} 4$ grown on glucose for $24 \mathrm{~h}\left(0.203 \mathrm{~g} \mathrm{~g}^{-1}\right.$ substrate consumed) and acetate during $72 \mathrm{~h}\left(0.016 \mathrm{~g} \mathrm{~g}^{-1}\right.$ substrate consumed), respectively (Table 1). For R. opacus PD630 the highest yield was obtained at $72 \mathrm{~h}$ using glucose as carbon source, whereas hexadecane was the most unsuitable carbon source, resulting in the lowest yield. As for the TAG content, increasing the accumulation period length from 24 to $72 \mathrm{~h}$ also influenced TAG yield in $R$. opacus B4 growing on acetate, resulting in a 3.4-fold decrease. TAG yield, in $R$. opacus PD630 was not affected under the same conditions.

With hexadecane, $R$. opacus B4 presented similar yields for both incubation periods, 2 and 5 fold higher yields than $R$. opacus PD630 ( $\mathrm{p}<0.05)$ for 24 and $72 \mathrm{~h}$ respectively. In $R$. opacus PD630 a $47 \%$ decrease was observed after $72 \mathrm{~h}$.

\section{Fatty acid composition of biomass and TAG produced}

Fatty acid composition of intact cells was not influenced by incubation time but drastically affected by the substrate used (Table 2). With glucose and acetate, and for both strains, fatty acids varied from 14 to 18 carbon atoms, being hexadecanoic acid (C16:0) the predominant one. In $R$. opacus $\mathrm{B} 4$ the fraction of saturated fatty acids was about $65 \%$ and odd numbered fatty acids accounted for about 40 and $50 \%$ for glucose and acetate, respectively, whereas in $R$. opacus PD630 these fractions were 35 and $55 \%$, respectively.

For hexadecane, fatty acids with lower carbon chains (C10-C16) were mainly detected, being hexadecanoic (C16:0) and hexadecenoic (C16:1) acids the predominant ones. In both strains, even-numbered fatty acids were $100 \%$.

Comparing both strains for glucose and acetate, the main differences were obtained for the percentage of C16:1 that was approximately two-fold higher in $R$. opacus PD630 than in R. opacus $\mathrm{B} 4$, and of $\mathrm{C} 17: 0$, that

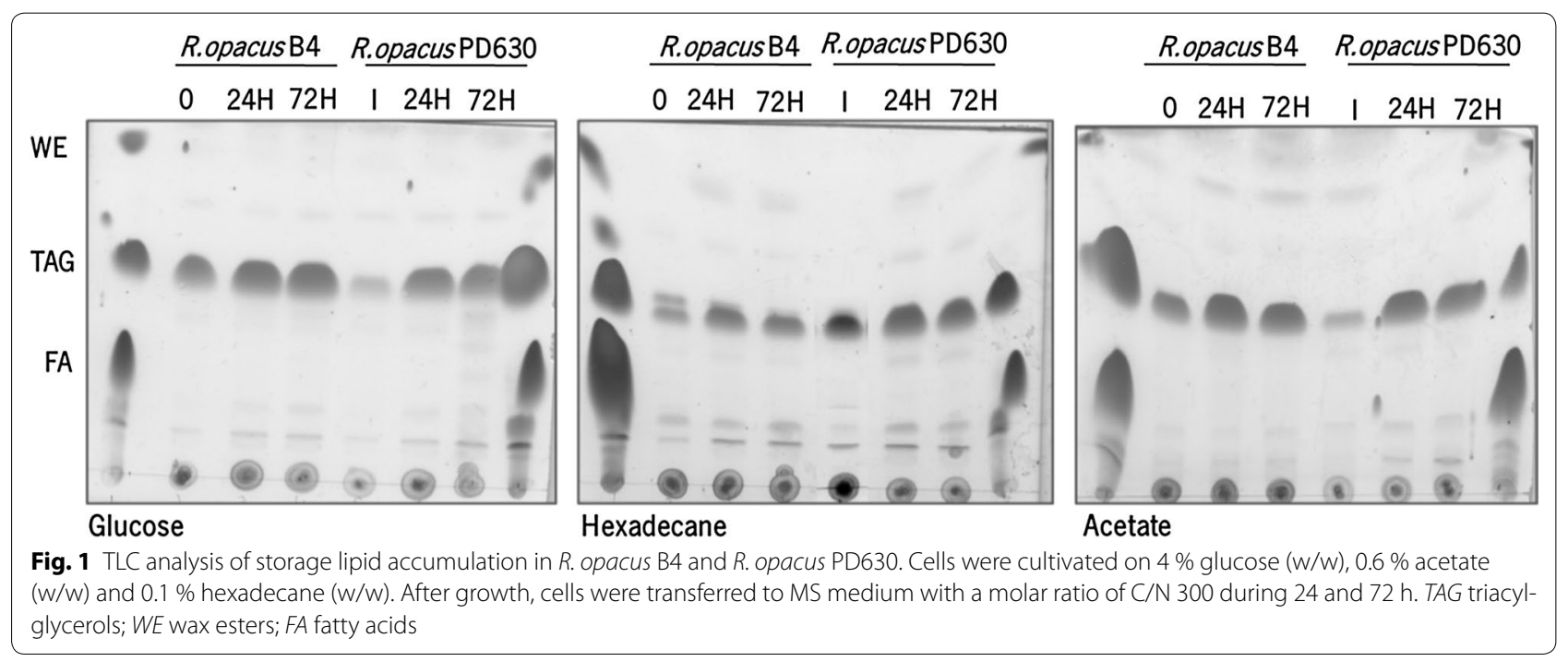




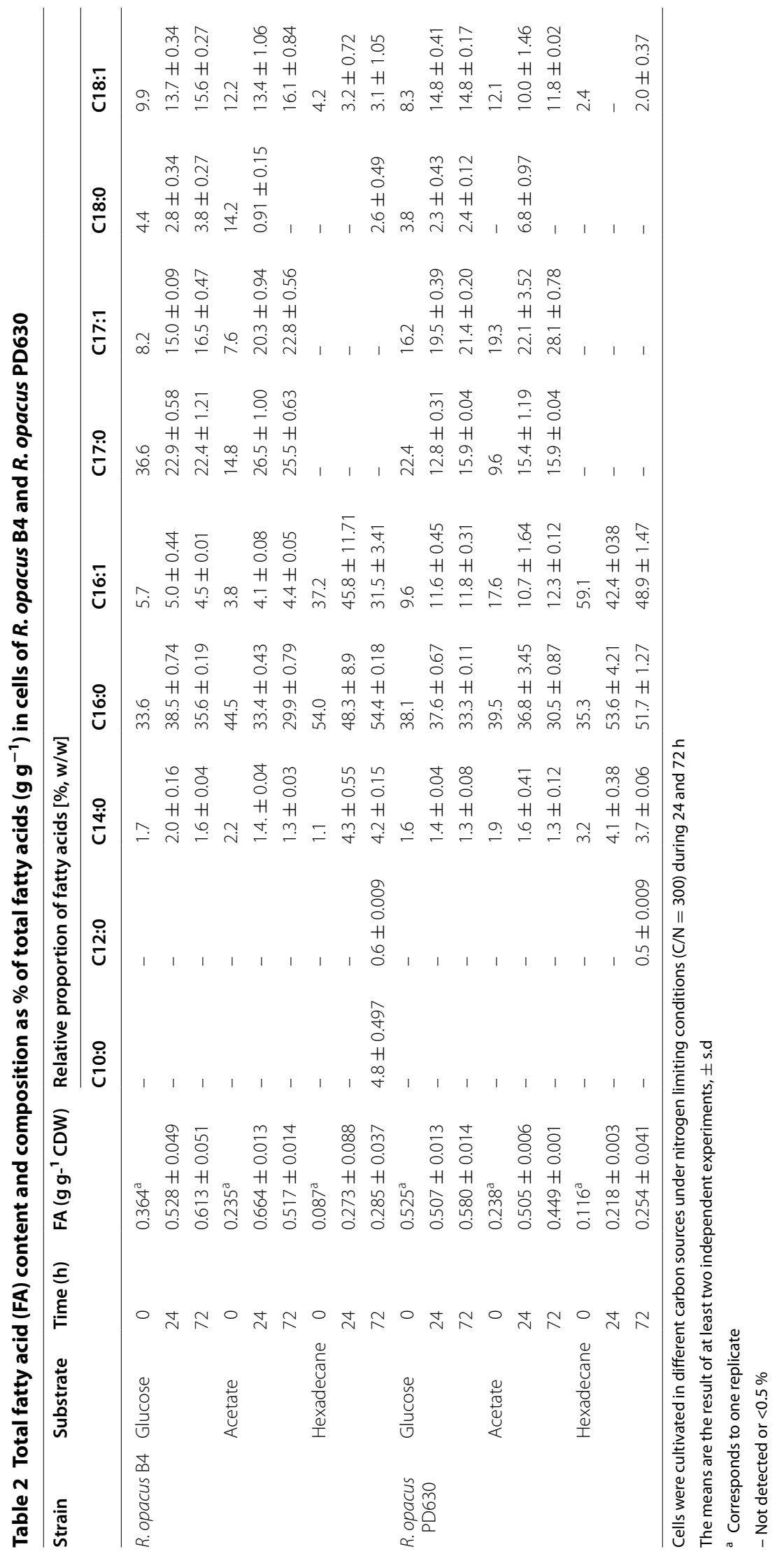


corresponded to around 23 to $27 \%$ of the fatty acids present in $R$. opacus $\mathrm{B} 4$ and around 13 to $16 \%$ in $R$. opacus PD630 ( $\mathrm{p}<0.05)$. With hexadecane, decanoic acid (C10:0), dodecanoic acid (C12:0) and stearic acid (C18:0) were only detected in $R$. opacus $\mathrm{B} 4$.

The fatty acid patterns of produced TAG fraction showed some important differences, depending on the strain, accumulation period length and carbon source used (Table 3). In both strains cultivated on glucose and acetate, the most dominant fatty acids were C16:0 (35 to $55 \%$ ) and C17:0, ranging between 15 and $40 \%$ for glucose, and between 35 and $50 \%$ for acetate. For hexadecane, the predominant fatty acids were C10:0 (almost $30 \%$ ) and $\mathrm{C} 16: 0$ (55 \%) in R. opacus B4, and C16:0 (85 \%) in $R$. opacus PD630. In R. opacus B4, the fraction of saturated fatty acids was similar for all carbon sources, reaching 90 to $96 \%$. Even-numbered fatty acids were 55 to $65 \%$ for glucose and acetate, and $100 \%$ for hexadecane. In $R$. opacus PD630, with hexadecane, no odd-numbered fatty acids were detected either, and 60 to $70 \%$ of evennumbered fatty acids were found with glucose and acetate. In both strains cultivated on glucose, there was a transition between saturated and unsaturated fatty acids from 24 to $72 \mathrm{~h}$ incubation length. $\mathrm{C} 10: 0$ and $\mathrm{C} 12: 0$ were only detected in $R$. opacus B4. TAG from $R$. opacus B4 cultivated on glucose and acetate had a higher percentage of C17:0 (39 and $48 \%$, respectively) than from $R$. opacus PD630 (16 and $38 \%$ ). In contrast, in R. opacus PD630 TAG contained higher percentages of C14:0 (13 \%); C16:0 (86 \%) and C16:1 (39\%) when compared to those of $R$. opacus B4 in hexadecane.

\section{Discussion}

This study contributes to increase the knowledge of TAG metabolism and physiology in Rhodococcus sp., but for practical applications, it is important to analyze global volumetric TAG productions and to extract objective conclusion with interest for industrial and environmental biotechnological applications.

$R$. opacus B4 showed a TAG production capability from hexadecane 3.3 fold higher than the volumetric production obtained by $R$. opacus PD630 (0.14 versus $0.043 \mathrm{~g}$ $\mathrm{L}^{-1}$ at $72 \mathrm{~h}$ cultivation time). This is relevant as this strain was never reported to accumulate TAG although it was reported to be able to transform and degrade several types of hydrocarbons and to stabilize water-oil phases (Na et al. 2005; Yamashita et al. 2007; Honda et al. 2008; Sameshima et al. 2008). For acetate, both strains showed similar maximal TAG volumetric productions (about $0.3 \mathrm{~g} \mathrm{~L}^{-1}$ ). In $R$. opacus $\mathrm{B} 4$ acetate consumption was faster, and the exhaustion of the external carbon source likely induced the decrease observed in TAG levels for the longest incubation period (72 h), due to its mobilization for cell maintenance. TAG's use as internal carbon and energy source has been also reported by Alvarez et al. (2000) in $R$. opacus PD630 and in $R$. ruber NCIMB 40126 cultivated on gluconate and glucose, after depletion of these carbons sources. With glucose, $R$. opacus PD630 showed about 2 fold the production obtained for $R$. opacus B4 in the same incubation periods (1.1 and $\left.1.6 \mathrm{~g} \mathrm{~L}^{-1}\right)$.

The type of carbon source is one of the most determinant factor influencing fatty acid content and composition in bacteria. $R$. opacus B4 presented a higher level of total fatty acids (intact cells) when cultivated on glucose or acetate than in hexadecane, and exhibited higher percentages than $R$. opacus PD630.

Taking into account the results obtained, $R$. opacus $\mathrm{B} 4$ can be considered an oleaginous bacterium, since it can accumulate more than $20 \%$ of biomass as lipids. There are several studies in literature reporting fatty acid accumulation in several Rhodococcus species using these substrates, ranging between 3.8 and $48.4 \%$ for glucose (Alvarez et al. 1997a; Shields-Menard et al. 2015), 21 and $31 \%$ for acetate (Hernandez et al. 2008; Hori et al. 2009) and between 8.1 and $43.4 \%$ for hexadecane (Alvarez 2003). Table 4 gives an overview of total (whole cell) fatty acid composition reported for different Rhodococcus highlighting the FA production potential of $R$. opacus B4 herein reported for the first time.

In general, the results obtained for fatty acid content in the produced TAG fraction are in agreement with the ones obtained for intact cells and a high variability of fatty acids was obtained, influenced by the type of carbon source used. When cells were cultivated on hexadecane, only even-numbered fatty acids were detected in the produced TAG, being C16:0 the dominant one. This suggests that the fatty acids produced were directly related to the chain length of the carbon source and to $\beta$-oxidation pathway, where acetate $(\mathrm{C} 2)$ is repeatedly removed, and agrees with other works (Alvarez et al. 1996; Alvarez et al. 1997a; Gouda et al. 2008; Hernandez et al. 2008; Silva et al. 2010). TAG composition can be very diverse among different species or even among strains of the same species in Rhodococcus genus, depending on genetic and metabolic machinery present in each organism (Alvarez et al. 2013). In R. opacus B4 shorter even-numbered fatty acids were detected in TAG, likely due to the presence of several DGAT enzymes that can have different substrate specificities in this strain compared to strain PD630 (Villalba et al. 2013). In the case of acetate and glucose, C16:0 and C17:0 were the dominant fatty acids, with higher percentage in R. opacus B4. These substrates can be converted into acetyl-CoA which is the precursor of de novo fatty acid synthesis pathway. Presence of odd-numbered fatty acids can result from the presence of an effective 


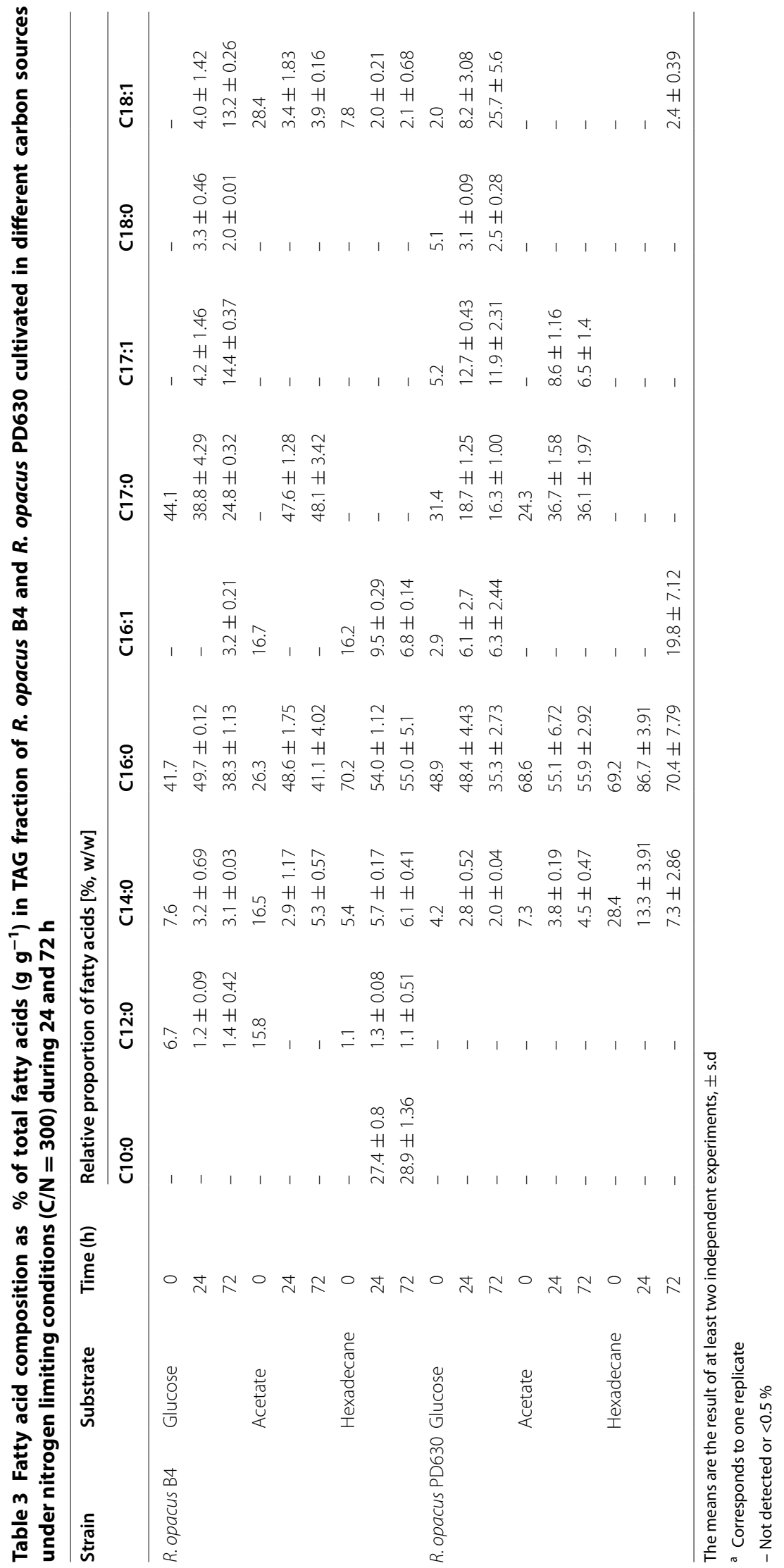


Table 4 Comparison of total fatty acids production between different lipid accumulating Rhodococcus using sugar, organic acid and hydrocarbon defined substrates

\begin{tabular}{|c|c|c|c|c|c|}
\hline Strain & Substrate & Incubation time (h) & $\mathrm{FA}\left(\mathrm{g} \mathrm{g}^{-1} \mathrm{CDW}^{\mathrm{a}}\right)$ & $F A\left(g^{-1}\right)$ & Reference \\
\hline \multirow[t]{4}{*}{ R. opacus B4 } & \multirow[t]{2}{*}{ Glucose $\left(40 \mathrm{~g} \mathrm{~L}^{-1}\right)$} & 24 & 0.528 & 0.600 & \multirow[t]{8}{*}{ This study ${ }^{b}$} \\
\hline & & 72 & 0.613 & 0.700 & \\
\hline & Acetate $\left(6 \mathrm{~g} \mathrm{~L}^{-1}\right)$ & 24 & 0.664 & 0.300 & \\
\hline & Hexadecane $\left(1 \mathrm{~g} \mathrm{~L}^{-1}\right)$ & 24 & 0.273 & 0.090 & \\
\hline \multirow[t]{11}{*}{ R. opacus PD630 } & \multirow[t]{2}{*}{ Glucose $\left(40 \mathrm{~g} \mathrm{~L}^{-1}\right)$} & 24 & 0.507 & 1.1 & \\
\hline & & 72 & 0.580 & 1.6 & \\
\hline & Acetate $\left(6 \mathrm{~g} \mathrm{~L}^{-1}\right)$ & 24 & 0.505 & 0.270 & \\
\hline & Hexadecane $\left(1 \mathrm{~g} \mathrm{~L}^{-1}\right)$ & 24 & 0.218 & 0.045 & \\
\hline & Glucose $\left(16 \mathrm{~g} \mathrm{~L}^{-1}\right)^{c}$ & 72 & 0.516 & 2.87 & Kurosawa and Sinskey (2013) \\
\hline & Glucose $\left(240 \mathrm{~g} \mathrm{~L}^{-1}\right)$ & 147 & 0.380 & 25.2 & Kurosawa et al. (2010) \\
\hline & Glucose $\left(10 \mathrm{~g} \mathrm{~L}^{-1}\right)$ & 12 & 0.198 & & Kosa and Ragauskas (2012) \\
\hline & Glucose $\left(40 \mathrm{~g} \mathrm{~L}^{-1}\right)$ & 96 & 0.412 & & MacEachran et al. (2010) \\
\hline & Glucose $\left(40 \mathrm{~g} \mathrm{~L}^{-1}\right)$ & 120 & 0.378 & & MacEachran and Sinskey (2013) \\
\hline & Acetate $\left(6 \mathrm{~g} \mathrm{~L}^{-1}\right)$ & 24 & 0.310 & & Alvarez et al. (1997a) \\
\hline & Hexadecane $\left(1 \mathrm{~g} \mathrm{~L}^{-1}\right)$ & 48 & 0.380 & & \\
\hline \multirow[t]{2}{*}{ R. opacus DSM1069 } & \multirow[t]{2}{*}{ Glucose $\left(10 \mathrm{~g} \mathrm{~L}^{-1}\right)$} & 12 & 0.216 & 0.244 & Wei et al. (2015) \\
\hline & & 120 & 0.179 & & Kosa and Ragauskas (2012 \\
\hline \multirow[t]{3}{*}{ R. ruber NCIMB 40126} & \multirow[t]{2}{*}{ Glucose $\left(10 \mathrm{~g} \mathrm{~L}^{-1}\right)$} & 24 & 0.190 & & Alvarez et al. (1997a) \\
\hline & & 84 & 0.380 & & Alvarez et al. (2000) \\
\hline & Hexadecane $\left(1 \mathrm{~g} \mathrm{~L}^{-1}\right)$ & 24 & 0.260 & & \\
\hline \multirow[t]{2}{*}{ Rhodococcus sp. A5 } & Glucose $\left(10 \mathrm{~g} \mathrm{~L}^{-1}\right)$ & 72 & 0.176 & & \multirow[t]{2}{*}{ Bequer Urbano et al. (2013) } \\
\hline & Hexadecane $\left(1 \mathrm{~g} \mathrm{~L}^{-1}\right)$ & 72 & 0.283 & & \\
\hline \multirow[t]{3}{*}{ R. fascians 123} & Glucose $\left(10 \mathrm{~g} \mathrm{~L}^{-1}\right)$ & 24 & 0.038 & & \multirow[t]{2}{*}{ Alvarez et al. (1997a) } \\
\hline & Hexadecane $\left(1 \mathrm{~g} \mathrm{~L}^{-1}\right)$ & 24 & 0.181 & & \\
\hline & & 72 & 0.129 & & Alvarez (2003) \\
\hline \multirow[t]{2}{*}{ R. erythropolis 17} & & 72 & 0.434 & & \\
\hline & & 24 & 0.176 & & Alvarez et al. (1997a) \\
\hline Rhodococcus sp. 20 & & 72 & 0.081 & & Alvarez (2003) \\
\hline \multirow[t]{2}{*}{ R. aetherivorans IAR1 } & Acetate $\left(9 \mathrm{~g} \mathrm{~L}^{-1}\right)$ & 80 & 0.240 & & \multirow[t]{2}{*}{ Hori et al. (2009) } \\
\hline & Toluene $\left(0.5 \mathrm{~g} \mathrm{~L}^{-1}\right)$ & 50 & 0.240 & & \\
\hline Rhodococcus sp. 602 & Hexadecane $\left(1 \mathrm{~g} \mathrm{~L}^{-1}\right)$ & 48 & 0.223 & & Silva et al. (2010) \\
\hline R. rhodochrous & Glucose $\left(20 \mathrm{~g} \mathrm{~L}^{-1}\right)$ & 168 & 0.430 & 3.030 & Shields-Menard et al. (2015) \\
\hline \multirow[t]{3}{*}{ R. jostii RHA1 } & Glucose (nr) & $\mathrm{nr}$ & 0.484 & & \multirow[t]{3}{*}{ Hernandez et al. (2008) } \\
\hline & Acetate (nr) & $\mathrm{nr}$ & 0.212 & & \\
\hline & Hexadecane (nr) & $\mathrm{nr}$ & 0.304 & & \\
\hline
\end{tabular}

a Cellular dry weight

b Conditions with possible substrate limitation are not included

c Engineered R. opacus PD630 strain to utilize xylose

$n r$ not reported

methylmalonyl-CoA production through succinyl-CoA (derived from TCA cycle), resulting in the formation of propionyl-coA, a 3-carbon molecule, which is a precursor for the synthesis of odd-numbered fatty acids. Several Rhodococcus species exhibited similar pattern (Alvarez et al. 1996, 1997a; Alvarez 2003; Hernandez et al. 2008; Holder et al. 2011).
Rhodococcus opacus B4 produced a high content of lipids, mainly composed by fatty acids ranging between $\mathrm{C} 16$ and $\mathrm{C} 18$ and revealed a high proportion of saturated acids over unsaturated ones. These properties are identical to the ones of traditional vegetable oils currently applied in biodiesel industry, namely canola, palm, sunflower, soybean and rapeseed oils (El-Hawa et al. 2004; 
Moser 2008). This suggests that $R$. opacus B4 can be exploited for high quality biodiesel-compatible fatty acids production (Ramos et al. 2009).

Furthermore, the production of TAG containing shorter fatty acids, namely decanoic acid (C10:0) by $R$. opacus B4 is an interesting feature. Decanoic acid (capric acid) is a saturated fatty acid that can be used in different types of industrial and commercial applications mainly due to its different chemical properties. This medium chain fatty acid is used in the production of creams and lotions in the personal care industry (Zielinska and Nowak 2014), as well as in the production of artificial flavors and aromas in the food and beverage industry (Saerens et al. 2008). In the pharmaceutical industry it is used as an antiviral and antimicrobial agent and also as a vasodilator (German and Dillard 2014). Additionally, it is applied in the textile industry and dyes production and is also useful in the production of synthetic rubber. It can be used as a plasticizer in the manufacture of a wide range of plastics and lubricating grease. In nature, capric acid can only be found in coconut oil, palm kernel oil and in goat, cow and human milks. Growing demand for those products around the world will require an increasing demand for capric acid in the next years, according to Global Capric Acid Market for Artificial Fruit Flavors and Perfumes, Pharmaceuticals and Chemical Syntheses (Lubricants, Greases, Rubber, Dyes, Plastics, etc.) 2014-2020 report (2016). Scarcity in availability of raw materials will be a relevant challenge to the development of capric acid based industry. Therefore, $R$. opacus B4 can be considered as a valuable alternative to the bioprocesses based on edible feedstocks.

Although focus on current research has been much directed to increase TAG production in R opacus PD630, such as running the process at a higher scale (Kurosawa et al. 2010), as well as to perform metabolic engineering studies (Hetzler and Steinbüchel 2013; Kurosawa et al. 2013, 2015a, 2015b), new strains of Rhodococcus opacus should be also considered and explored for similar abilities. In particular the strain studied in this work, $R$. opacus B4, shows relevant interest in TAG production from liquid hydrocarbons, herein demonstrated with hexadecane as a model alkane. Combining TAG production with hydrocarbons degradation is a powerful strategy to achieve environmental remediation while producing added value compounds.

In conclusion, the obtained results contribute to increase the knowledge of TAG metabolism and physiology in Rhodococcus sp. and open new perspectives for the use of $R$. opacus B4 to produce triacylglycerol with fatty acids composition relevant for industrial purposes, in particular using abundant recalcitrant residues like alkane-based wastewater as cheap raw-material.

\section{Abbreviations}

CDW: cellular dry weight; FA: fatty acids; FID: flame ionization detector; MS mineral salts; nm: nanometers; PHA: polyhydroxyalkanoates; s.d.: standard deviation; Rf: retention factor; TAG: triacylglycerols; TLC: thin layer chromatography; WE: wax esters; w/w: weight/weight.

\section{Authors' contributions}

All authors contributed intellectually via scientific discussions during the work and have been involved in drafting the manuscript and revising it critically for important intellectual content. ARC helped to design the experiments, performed all the experimental work, analysed and interpreted data and wrote the manuscript. IR and MMA participated in the interpretation of data and reviewed the manuscript. MAP designed the experiments, supervised all the experimental work, contributed to data interpretation and reviewed the manuscript. All authors read and approved the final manuscript.

\section{Competing interests}

The authors declare that they have no competing interests.

\section{Ethical statement}

This article does not contain any studies with human participants or animals performed by any of the authors.

\section{Funding}

This work was financially supported by the Portuguese Science Foundation (FCT) and European Social Fund (ESF, POPH-QREN) through the Grant given to A.R. Castro (SFRH/BD/64500/2009), the FCT Strategic Project of UID/ BIO/04469/2013 unit and COMPETE 2020 (POCI-01-0145-FEDER-006684) and project RECI/BBB-EBI/0179/2012 (FCOMP-01-0124-FEDER-027462).

Received: 6 May 2016 Accepted: 7 May 2016

Published online: 14 May 2016

\section{References}

Alvarez H. Relationship between beta-oxidation pathway and the hydrocarbon-degrading profile in actinomycetes bacteria. Int Biodeterior Biodegr. 2003;52:35-42. doi:10.1016/50964-8305(02)00120-8.

Alvarez H, Kalscheuer R, Steinbüchel A. Accumulation of storage lipids in species of Rhodococcus and Nocardia and effect of inhibitors and polyethylene glycol. Fett/Lipid. 1997a;99:239-46.

Alvarez H, Kalscheuer R, Steinbüchel A. Accumulation and mobilization of storage lipids by Rhodococcus opacus PD630 and Rhodococcus ruber NCIMB 40126. Appl Microbiol Biotechnol. 2000;54:218-23. doi:10.1002/ lipi.19970990704.

Alvarez H, Mayer F, Fabritius D, Steinbüchel A. Formation of intracytoplasmic lipid inclusion by Rhodococcus opacus PD630. Arch Microbiol. 1996;165:377-86. doi:10.1007/s002030050341.

Alvarez H, Silva RA, Herrero M, Hernandéz MA, Villalba MS. Metabolism of triacylglycerols in Rhodococcus species: insights from physiology and molecular genetics. J Mol Biochem. 2013;2:69-78.

Alvarez H, Steinbüchel A. Physiology, biochemistry, and molecular biology of triacylglycerol accumulation by Rhodococcus. In: Alvarez HM editors. Biology of Rhodococcus, vol 16. Microbiology monographs. Berlin Heidelberg: Springer; 2010. pp 263-90. doi:10.1007/978-3-642-12937-7_10.

Alvarez HM, Pucci OH, Steinbüchel A. Lipid storage compounds in marine bacteria. Appl Microbiol Biot. 1997b;47:132-9. doi:10.1007/s002530050901.

Alvarez HM, Steinbüchel A. Triacylglycerols in prokaryotic microorganisms. Appl Microbiol Biot. 2002;60:367-76. doi:10.1007/s00253-002-1135-0.

Bequer Urbano S, Albarracín VH, Ordoñez OF, Farías ME, Alvarez HM. Lipid storage in high-altitude Andean Lakes extremophiles and its mobilization under stress conditions in Rhodococcus sp. A5, a UV-resistant actinobacterium. Extremophiles. 2013;17:217-77. doi:10.1007/s00792-012-0508-2.

Brandl H, Goss RA, Lenz RW, Fuller RC. Pseudomonas oleovorans as a source of poly(beta-hydroxyalkanoates) for potential applications as biodegradable polyesters. Appl Environ Microbiol. 1988;54:1977-82.

El-Hawa SHA, Ragab WS, El-Dengawy RA, Ali FF. Composition of Canola seed oil. Yemeni J Medical Sci. 2004;6(1):25-35. 
Folch J, Lees M, Sloane Stanley G. A simple method for the isolation and purifcation of total lipides from animal tissues. J Biol Chem. 1957;226:497-509.

German J, Dillard CJ. Saturated fats: what dietary intake? Am J Clin Nutr. 2014:80:550-9.

Global capric acid market for artificial fruit flavors and perfumes, pharmaceuticals and chemical syntheses (lubricants, greases, rubber, dyes, plastics, etc.) 2014-2020 report. http://www.marketresearchstore.com/report/globalcapric-acid-market-for-artificial-fruit-flavors-34817. Accessed 6 Apr 2016.

Gouda M, Omar S, Aouad L. Single cell oil production by Gordonia sp. DG using agro-industrial wastes. World J Microbiol Biotechnol. 2008;24:170311. doi:10.1007/s11274-008-9664-z.

Hamada T, Maeda Y, Matsuda H, Sameshima Y, Honda K, Omasa T, Kato J, Ohtake H. Effect of cell-surface hydrophobicity on bacterial conversion of water-immiscible chemicals in two-liquid-phase culture systems. J Biosci Bioeng. 2009;108:116-20. doi:10.1016/j.jbiosc.2009.03.009.

Heald S, Brandão PB, Hardicre R, Bull A. Physiology, biochemistry and taxonomy of deep-sea nitrile metabolising Rhodococcus strains. Antonie Van Leeuwenhoek. 2001;80:169-83. doi:10.1023/a:1012227302373.

Hernandez M, Mohn W, Martinez E, Rost E, Alvarez A, Alvarez H. Biosynthesis of storage compounds by Rhodococcus jostii RHA1 and global identification of genes involved in their metabolism. BMC Genom. 2008;9:600. doi:10.1186/1471-2164-9-600.

Hetzler S, Steinbüchel A. Establishment of cellobiose utilization for lipid production in Rhodococcus opacus PD630. Appl Environ Microbiol. 2013;79:3122-5. doi:10.1128/aem.03678-12.

Holder JW, Ulrich JC, DeBono AC, Godfrey PA, Desjardins CA, Zucker J, Zeng Q, Leach AL, Ghiviriga I, Dancel C, Abeel T, Gevers D, Kodira CD, Desany B, Affourtit JP, Birren BW, Sinskey AJ. Comparative and functional genomics of Rhodococcus opacus PD630 for biofuels development. PLoS Genet. 2011;7:e1002219. doi:10.1371/journal.pgen.1002219.

Honda K, Yamashita S, Nakagawa H, Sameshima Y, Omasa T, Kato J, Ohtake H. Stabilization of water-in-oil emulsion by Rhodococcus opacus B-4 and its application to biotransformation. Appl Microbiol Biot. 2008;78:767-73. doi:10.1007/s00253-008-1378-5.

Hori K, Abe M, Unno H. Production of triacylglycerol and poly(3-hydroxybutyrate-co-3-hydroxyvalerate) by the toluene-degrading bacterium Rhodococcus aetherivorans IAR1.J Jiosci Bioeng. 2009;108:319-24. doi:10.1016/j.jbiosc.2009.04.020.

Kalscheuer R, Wältermann M, Alvarez H, Steinbüchel A. Preparative isolation of lipid inclusions from Rhodococcus opacus and Rhodococcus ruber and identification of granule-associated proteins. Arch Microbiol. 2001;177:20-8. doi:10.1007/s00203-001-0355-5.

Kosa M, Ragauskas A. Bioconversion of lignin model compounds with oleaginous Rhodococci. Appl Microbiol Biot. 2012;93:891-900. doi:10.1007/ s00253-011-3743-z.

Kurosawa K, Boccazzi P, de Almeida N, Sinskey AJ. High-cell-density batch fermentation of Rhodococcus opacus PD630 using a high glucose concentration for triacylglycerol production. J Biotechnol. 2010;147:212-8. doi:10.1016/j.jbiotec.2010.04.003.

Kurosawa K, Plassmeier J, Kalinowski J, Rückert C, Sinskey AJ. Engineering I-arabinose metabolism in triacylglycerol-producing Rhodococcus opacus for lignocellulosic fuel production. Metab Eng. 2015a;30:89-95. doi:10.1016/j.ymben.2015.04.006.

Kurosawa K, Plassmeier J, Sinskey AJ. Improved glycerol utilization by a triacylglycerol producing Rhodococcus opacus strain for renewable fuels. Biotechnol Biofuels. 2015b;8:31-42. doi:10.1186/s13068-015-0209-z.

Kurosawa K, Sinskey AJ. Engineering xylose metabolism in triacylglycerol producing Rhodococcus opacus for lignocellulosic fuel production. Biotechnol Biofuels. 2013;6:134-47. doi:10.1186/1754-6834-6-134.

Luz AP, Pellizari VH, Whyte LG, Greer CW. A survey of indigenous microbial hydrocarbon degradation genes in soils from Antarctica and Brazil. Can J Microbiol. 2004;50:323-33. doi:10.1139/w04-008.

MacEachran D, Prophete M, Sinskey AJ. The Rhodococcus opacus PD630 heparin-binding hemagglutinin homolog TadA mediates lipid body formation. Appl Environ Microbiol. 2010;76:7217-25. doi:10.1128/AEM.00985-10.

MacEachran D, Sinskey AJ. The Rhodococcus opacus TadD protein mediates triacylglycerol metabolism by regulating intracellular NAD(P)H pools. Microb Cell Fact. 2013;12:104. doi:10.1186/1475-2859-12-104.

Moser BR. Influence of blending canola, palm, soybean and sunflower oil methyl esters on fuel properties of biodiesel. Energ Fuel. 2008;22(6):4301-6.
Na KS, Kuroda A, Takiguchi N, Ikeda T, Ohtake H, Kato J. Isolation and characterization of benzene-tolerant Rhodococcus opacus strains. J Biosc Bioeng. 2005;99:378-82. doi:10.1263/jbb.99.378.

Packter NM, Olukoshi ER. Ultrastructural studies of neutral lipid localisation in Streptomyces. Arch Microbiol. 1995;164:420-7.

Peng F, Wang Y, Sun F, Liu Z, Lai Q, Shao Z. A novel lipopeptide produced by a Pacific Ocean deep-sea bacterium, Rhodococcus sp. TW53. J Appl Microbiol. 2008;105:698-705. doi:10.1111/j.1365-2672.2008.03816.x.

Ramos MJ, Fernández CM, Casas A, Rodríguez L, Pérez Á. Influence of fatty acid composition of raw materials on biodiesel properties. Bioresour Technol. 2009;100:261-8. doi:10.1016/j.biortech.2008.06.039.

Röttig A, Wenning L, Bröker D, Steinbüchel A. Fatty acid alkyl esters: perspectives for production of alternative biofuels. Appl Microbiol Biot. 2010;85:1713-33. doi:10.1007/s00253-009-2383-z.

Saerens SMG, Delvaux F, Verstrepen KJ, Van Dijckv P, Thevelein JM, Delvaux FR. Fermentation parameters affecting ethyl ester production by Saccharomyces cerevisiae during fermentation. Appl Environ Microbiol. 2008;74(2):54-461. doi:10.1128/AEM.01616-07.

Sameshima Y, Honda K, Kato J, Omasa T, Ohtake H. Expression of Rhodococcus opacus alkB genes in anhydrous organic solvents. J Biosc Bioeng. 2008;106:199-203. doi:10.1263/jbb.106.199.

Santala S, Efimova E, Kivinen V, Larjo A, Aho T, Karp M, Santala V. Improved triacylglycerol production in Acinetobacter baylyi ADP1 by metabolic engineering. Microb Cell Fact. 2011;10:36. doi:10.1186/1475-2859-10-36.

Schlegel H, Kaltwasser H, Gottschalk G. Ein Submersverfahren zur Kultur wasserstoffoxidierender Bakterien: Wachstumsphysiologische Untersuchungen. Arch Mikrobiol. 1961;38:209-22.

Shields-Menard S, Amirsadeghi M, Sukhbaatar B, Revellame E, Hernandez R, Donaldson J, French WT. Lipid accumulation by Rhodococcus rhodochrous grown on glucose. J Ind Microbiol Biotechnol. 2015;42:693-9. doi:10.1007/s10295-014-1564-7.

Silva RA, Grossi V, Olivera NL, Alvarez HM. Characterization of indigenous Rhodococcus sp. 602, a strain able to accumulate triacylglycerides from naphthyl compounds under nitrogen-starved conditions. Res Microbiol. 2010;161:198-207. doi:10.1016/.resmic.2010.01.007.

Steinbüchel A, Hein S Biochemical and Molecular Basis of Microbial Synthesis of Polyhydroxyalkanoates in Microorganisms. In: Babel W, Steinbüchel A editors Biopolyesters, advances in biochemical engineering/biotechnology. Berlin Heidelberg: Springer, vol 71 pp 81-123. doi:10.1007/3-540-40021-4_3.

Timm A, Byrom D, Steinbüchel A. Formation of blends of various poly(3hydroxyalkanoic acids) by a recombinant strain of Pseudomonas oleovorans. Appl Microbiol Biot. 1990;33:296-301. doi:10.1007/bf00164525.

Villalba MS, Hernandéz MA, Silva RA, Alvarez H. Genome sequences of triacylglycerol metabolism in Rhodococcus as a platform for comparative genomics. J Mol Biochem. 2013;2:94-105.

Voss I, Steinbuchel A. High cell density cultivation of Rhodococcus opacus for lipid production at a pilot-plant scale. Appl Microbiol Biot. 2001;55:547-55.

Wältermann M, Hinz A, Robenek H, Troyer D, Reichelt R, Malkus U, Galla HJ, Kalscheuer R, Stöveken T, von Landenberg P, Steinbüchel A. Mechanism of lipid-body formation in prokaryotes: how bacteria fatten up. Mol Microbiol. 2005;55:750-63.

Wältermann M, Luftmann H, Baumeister D, Kalscheuer R, Steinbüchel A. Rhodococcus opacus strain PD630 as a new source of high-value single-cell oil? Isolation and characterization of triacylglycerols and other storage lipids. Microbiology. 2000;146:1143-9.

Wei Z, Zeng G, Huang F, Kosa M, Sun Q, Meng X, Huang D, Ragauskas AJ. Microbial lipid production by oleaginous Rhodococci cultured in lignocellulosic autohydrolysates. Appl Microbiol Biotechnol. 2015;99:7369-77. doi:10.1007/s00253-015-6752-5.

Whyte LG, Slagman SJ, Pientratonio F, Bourbonnière L, Koval SV, Lawrence $J R$, Inniss WE, Greer CW. Physiological adaptations involved in alkane assimilation at a low remperature by Rhodococcus sp. strain Q15. Appl Environm Microbiol. 1999;65:2961-8.

Yamashita S, Satoi M, Iwasa Y, Honda K, Sameshima Y, Omasa T, Kato J, Ohtake H. Utilization of hydrophobic bacterium Rhodococcus opacus B-4 as whole-cell catalyst in anhydrous organic solvents. Appl Microbiol Biot. 2007;74:761-7. doi:10.1007/s00253-006-0729-3.

Zielinska A, Nowak I. Fatty acids in vegetable oils and their importance in cosmetic industry. Chemik. 2014;68:103-10. 